\title{
REVIEW
}

\section{Diving into the world of biologging}

\author{
Yan Ropert-Coudert ${ }^{1, *}$, Michael Beaulieu ${ }^{1}$, Nicolas Hanuise ${ }^{1,2}$, Akiko Kato ${ }^{1}$ \\ ${ }^{1}$ Institut Pluridisciplinaire Hubert Curien, Departement Ecologie, Physiologie and Ethologie, 23 rue Becquerel, \\ 67087 Strasbourg Cedex, France \\ ${ }^{2}$ Centre d'Etudes Biologiques de Chizé, Villiers-en-Bois, 79360 Beauvoir-sur-Niort, France
}

\begin{abstract}
On the occasion of the publication of the proceedings of the Third International Biologging Science Symposium, we present a summary of the incidence of biologging in studies of animal behaviour. Studies investigating diving activity were used as a proxy to examine the use of a biologging technology. Specifically, studies referenced in the Penguiness Book, an internet-based diving database, were used to examine: (1) on which taxa of diving animals biologging is principally used; (2) which countries are the principal users and producers of biologging technology; and (3) the incidence of this approach in peer-reviewed publications. Each of these items is discussed in the light of the intrinsic limitations of biologging approaches.
\end{abstract}

KEY WORDS: Retrospective study $\cdot$ Diving activity $\cdot$ Manufacturers $\cdot$ Publications $\cdot$ IUCN

\section{INTRODUCTION}

Biologging is the practice of attaching data-recording devices (e.g. biologgers, data storage tags, archival tags, electronic data recorders) to animals. This definition excludes all tracking devices such as radio or satellite tracking devices, although it includes those data-recording devices that can transmit their data at intervals. The approach is suggested to have emerged in the 1940s when a capillary depth gauge was attached by Pers Scholander onto a harpooned whale to gather information about the cetacean's maximum diving depth (Naito 2004). In this respect, biologging would thus be $>60 \mathrm{yr}$ old, but the technology has undergone a rapid development in the last $20 \mathrm{yr}$, accompanied by an increase and diversification in the user base, as indicated by the success of the 3 first symposia dedicated to this scientific field as well as the increasing number of reviews on the subject (e.g. Wilson et al. 2002, Cooke et al. 2004, 2008, Block 2005, Ropert-Coudert \& Wilson 2005, Burger \& Shaffer 2008). Furthermore, data from animal-attached devices are now featured widely in the media and have even been used as tools to garner public support for the plight of endangered species.
Over the past $20 \mathrm{yr}$, miniaturization and technological innovations have meant that biologging could be applied to smaller animals exploiting any type of environment (aquatic, terrestrial or aerial) and at almost all latitudes, thus allowing researchers to address an increasingly diverse panel of questions. For instance, Ropert-Coudert \& Wilson (2005) identified up to 24 different types of sensors in use in biologgers (solely or in groups). Compiling all biologging studies exhaustively would be a daunting task, if not an impossible one. We therefore decided to use a proxy for biologging that would be easily detectable in the literature but should still be representative of the whole discipline. We chose diving activity studies as a proxy since biologging finds its origin in the marine environment (e.g. Kooyman 2004) and investigations on diving animals represent the core of biologging studies, whether or not diving activity is the principal focus of the study (Rutz \& Hays 2009). Conveniently, a substantial portion of such studies have already been compiled in the air-breathing divers database (the Penguiness Book, Ropert-Coudert et al. 2006), allowing us to access a large amount of information pertinent to the present study. The present review is based on the 464 peerreviewed references entered in the database on 5 April 
2008. This database intends to collect as many diving data on free-ranging animals as exists in the peerreviewed literature, a source of reliable information. The major shortcoming in basing the following review on this database is that a number of references of biologging applied to captive species or to non airbreathing species (e.g. fish) are not considered, but it would be unrealistic to try and collect all biologging papers exhaustively.

In the present review, we will use the Penguiness database to examine the following: (1) what and how often diving species have been studied through a biologging approach, noting the current limits of biologging applications; (2) the geographical distribution of producers and end-users of data-recording devices; and (3) the incidence of biologging in the scientific literature, through a detailed investigation of the journals in which studies using this approach were published.

\section{BIOLOGGING FOR WHICH SPECIES?}

In the current section we will only consider studies from the Penguiness Book that used biologging as a methodology (i.e. excluding all studies based on observations). The database recognises and contains data from 536 diving species (289 birds, 136 mammals, 111 reptiles), of which 130 have diving data documented (63 birds, 53 mammals, 14 reptiles). This information is contained in 422 diving studies, where species may be represented in more than one study (196 birds, 183 mammals, 43 reptiles). We first looked at the proportion of species that have been studied via biologging in a given taxon (Fig. 1). In terms of the total number of studies conducted, seabirds was by far the most investigated taxon. Yet the most studied taxon in terms of percentage of species studied within a taxon was that of the pinnipeds, followed by seabirds, while the least studied taxa were freshwater birds and sea snakes. These latter taxa actually comprise a substantial number of species; for instance, the latest taxonomic agreement proposes 75 species of sea snakes (Ineich 2004), of which only 3 studies investigated diving behaviour, none of them using biologgers (but see Brischoux et al. 2007, not compiled into the database). Within a taxon, the situation was also highly contrasted. For instance, seabird studies greatly outnumbered studies on freshwater birds. Similarly, penguins were overrepresented (86 studies out of 197 studies on seabirds), while there were almost no studies on Procellariiforms like petrels and shearwaters. The same situation was found in the marine mammal taxa, where most pinniped species were thoroughly investigated (all species of pinnipeds have been studied with the exception of the Japanese sea lion Zalophus japonicus, considered extinct) while biologging was rarely used to investigate cetaceans although 4 cetacean families are overrepresented: Monodontidae (beluga whales and narwhals), Balaenopteridae (rorquals), Phocoenidae (porpoises), and Physiteridae (sperm whales). Note that some taxa of diving, air-breathing animals have not yet been listed in the database (e.g. kingfishers, freshwater snakes, hippopotamuses, beavers), but this is mainly because

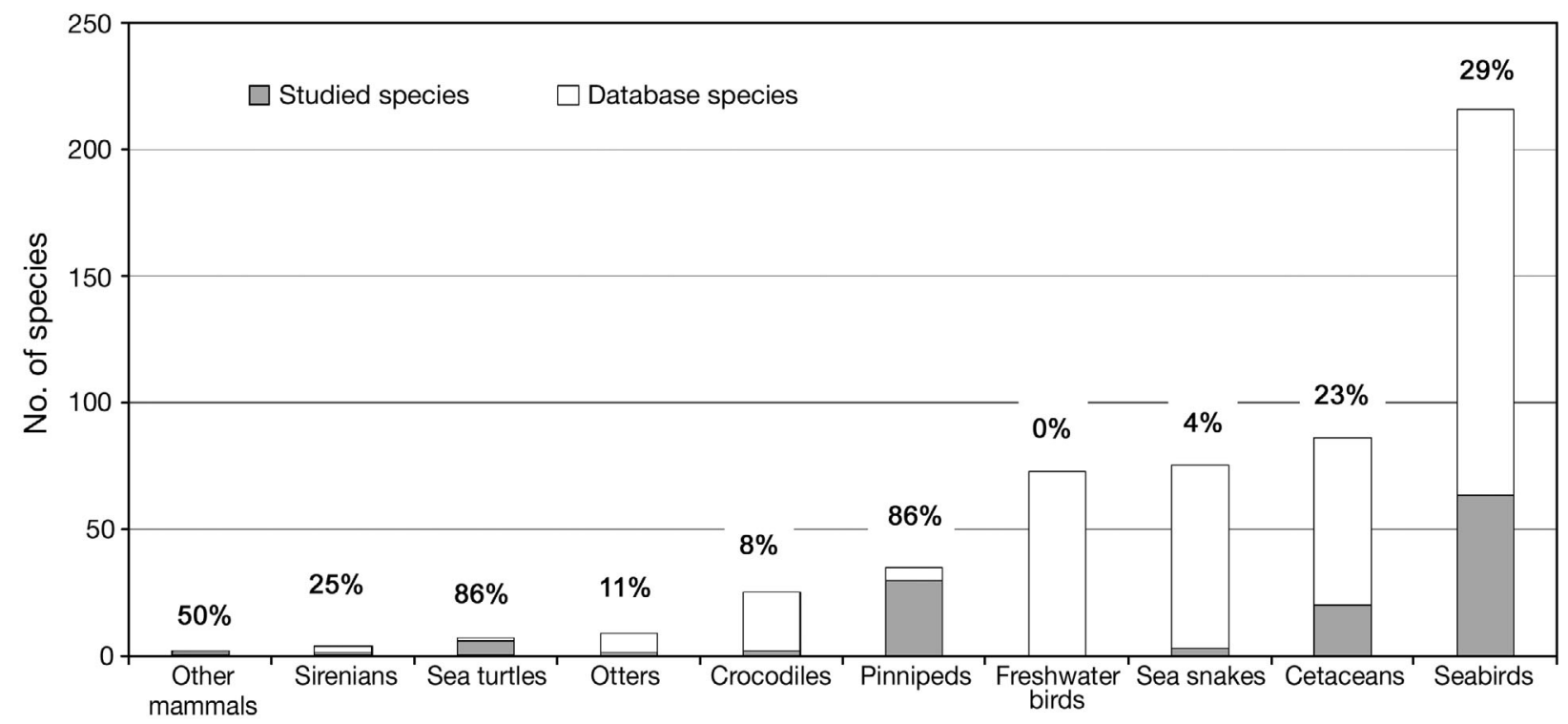

Fig. 1. Number of species considered in the Penguiness Book database (white bars) and the respective number of species for which diving activity has been investigated using a biologging approach (grey bars) for each taxon. The proportion that this latter number represents compared to the total number of species per taxon is written above the bars 
of the absence of literature on the diving abilities of these species.

Why are some species are more targeted than others? We presume that good candidates should be accessible, have a large body size and be available in appreciable numbers. All marine species that breed on land and return periodically ashore will be preferentially selected for biologging studies. Conversely, marine species that spend the majority of their time submerged are underrepresented, a situation that will change if researchers focus on designing new techniques for devices attachment and recovery. Similarly, it is not surprising that the most frequently studied species were large, e.g. elephant seals Mirounga spp., leatherback turtles Der-

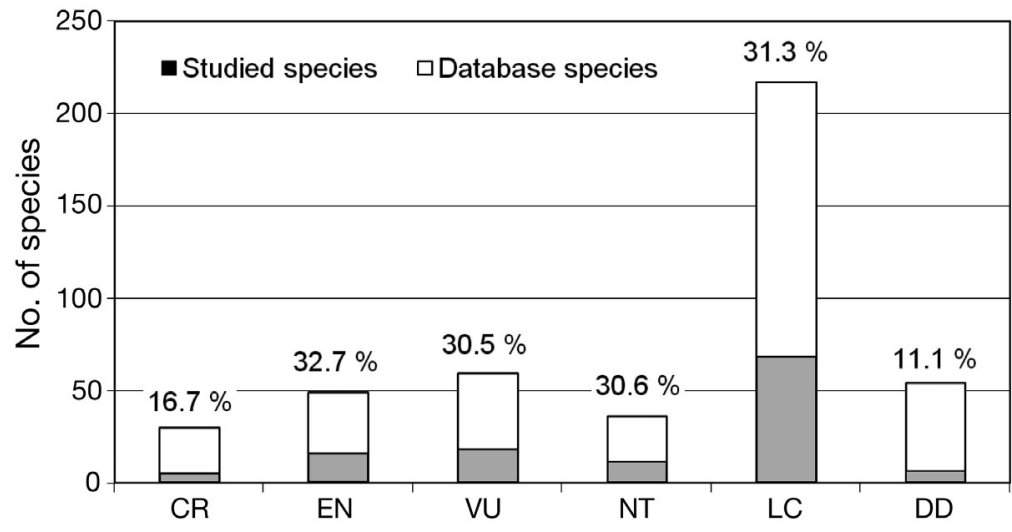

Fig. 2. Number of species considered in the Penguiness Book database (white bars) and the respective number of species for which diving activity has been investigated using a biologging approach (grey bars) according to conservation status, as defined in the 2008 IUCN Red List. CR: Critically Endangered; EN: Endangered; VU: Vulnerable; NT: Near Threatened, LC: Least Concern; DD: Data Deficient mochelys coriacea or narwahls Monodon monoceros, i.e. animals large enough to accommodate the early devices, which were bulkier than the present ones. Yet miniaturization has meant that body size becomes less critical. Moreover, preference was historically given to species that breed in large numbers at the same place, which offered an incomparable range of potential candidates to biologging investigations (e.g. penguin colonies where several thousands of individuals nest in the same bay). Finally, species that display extreme abilities are a good model since, for instance, the activity of a deep diver will be more conspicuous and thus easier to monitor, even with low accuracy devices, than that of a shallow diver, though the choice of the species should solely depend on the question being asked.

One important factor in the choice of a target species is the conservation status of the animal model (www. iucnredlist.org/search). Across all the different IUCN statuses the proportion of animals investigated via biologging was fairly constant at ca. 30\% (Fig. 2), with the exception of Critically Endangered species, for which this percentage decreased to $16 \%$. Thus biologging provides quantitative and reliable data from which relevant conservation and management procedures can be implemented. In this context, researchers are becoming more aware of deleterious effects caused by instruments (e.g. McMahon et al. 2008) and have proposed guidelines to minimize these effects as much as possible (for reviews see Hawkins 2004, Wilson \& McMahon 2006). It is important to note that in this section we used the 2008 IUCN status which may not reflect the status of the species when the relevant biologging study was conducted.

When all taxa are considered together, $66.4 \pm 30.2 \%$ of the studies analysed did not give any information about the sex of the individuals monitored. This proportion varies within each taxon, being least sex-specific in birds $(90.7 \%$ of studies do not distinguish between the sexes) where an appreciable number of species are monomorphic, but appreciable in cetaceans $(76.1 \%)$. Conversely, only $32.5 \%$ of studies on the highly dimorphic pinnipeds did not specify sex differences, while virtually $100 \%$ of sea turtle studies defined the sex of the study animals since most deployments are conducted on females coming ashore to lay their eggs. In seabirds, the characteristics of targeted individuals cannot be deduced from visual examination upon capture (e.g. male and female penguins look extremely alike), and all classes of individuals are not similarly accessible (e.g. older individuals tend to nest further inside a colony than younger ones, Ainley 1983). Yet individual-based approaches are important in ecology, as each individual within a population presents specific life-history traits that make it unique and will determine a specific physiological and behavioural response (Stearns 1992). To remedy this situation, a suite of new methodologies exists: for instance, modern genetic techniques using biological tissues (e.g. blood, skin, feathers) are affordable and enable workers to sex individuals reliably (e.g. Griffiths \& Tiwari 1993, Griffiths et al. 1998). Similarly, if most publications with age information only provide an indication on the age class (e.g. juveniles, young-of-theyear, or adults) and nothing about the precise age of the animal studied, work could be concentrated on known-age animals (e.g. previously marked using rings and/or transponders). The next generation of studies should clearly aim at applying biologging approaches onto known individuals so as to demonstrate the full potential of this discipline. 


\section{SOCIOECONOMIC CONTEXT OF BIOLOGGING}

At the end of the 20th century, the increased need to monitor animals in the wild has led to the emergence of the biologgers market. New types of applications have emerged thanks to a quick development of the technology involved. Who took advantage of this new development as a manufacturer or as a user of biologgers? Note again that only companies that produced devices used in studies in the Penguiness database will be considered in the present review (see 'Introduction'). Although we estimated that, to the best of our knowledge, all companies producing biologgers appeared in the analysis, an undefined number of biologging producers and users will not be mentioned, including, for example, those who study fish behaviour where the usage of such technology is substantial.

Articles in the Penguiness Book were first sorted by the type of tools used to monitor animals. They were then sorted by the nationality of the logger manufacturer and the nationality of the laboratory of the first author (Fig. 3). A total of $88 \%$ of studies used biologgers (sensu stricto, including $12 \%$ as capillary depth gauges) to monitor diving animals. The remaining $12 \%$ of studies reported the use of radio transmitters $(8.1 \%)$ and acoustic material (3.9\%). Among the $76 \%$ of studies using solid state devices (i.e. excluding capillary depth gauges that are usually custom built), American, European and Asian companies shared the market of loggers with $56.1 \%$ of loggers produced by Northern American companies and 13.3 and $11.2 \%$ by Japanese and European companies, respectively. In fact, the majority of biologgers used in the studies analysed were manufactured in 6 countries: the US $(51.5 \%)$, Japan $(13.3 \%)$, Germany $(5.2 \%)$, Canada

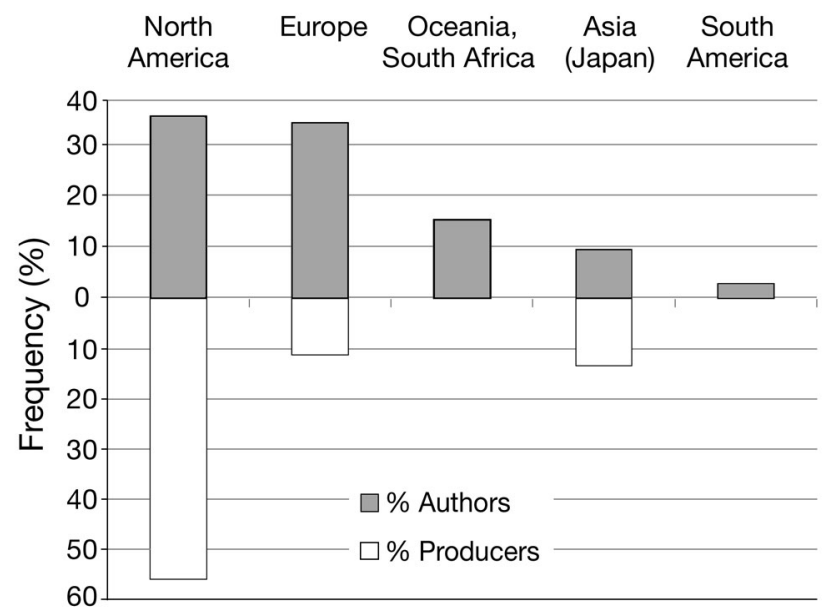

Fig. 3. Proportion of biologger manufacturers (white bars) and users (grey bars)
$(4.5 \%)$, the UK $(3.9 \%)$ and Italy $(2.1 \%)$. Because biologging research is driven by the desire to answer specific questions rather than simple use of the technology and due to the extreme specificity of biologgers, most producers may have originally been working in close association with, or even be part of, research institutions to develop custom-made tools. The use of these tools would naturally spread through collaborations, increasing the range of potential customers, to the point when production of biologgers would become viable for a company.

The spectrum of nationalities was wider for users ( $n=24)$ than for manufacturers $(n=6)$ of biologgers. However, the use of biologgers was confined to rich countries: $36.56 \%$ of authors worked in a North American laboratory, $35.24 \%$ in a European laboratory, $15.86 \%$ in Oceania or in South Africa, $9.91 \%$ in Japan and $3.08 \%$ in South America.

Within rich countries, the US dominated the production of biologgers and the number of biologging publications. In contrast, the number of publications in Europe was comparable but the production of loggers was anecdotal. The large number of publications relative to the level of biotechnology production in Europe likely reflects a reliance of European users on technology produced in other countries. However, it may also reflect researchers in Europe producing a higher number of publications per dataset (cf. King 2004). It would be worthwhile developing further biologging technology in Europe in order to diversify trade supply and to propose an alternative to purpose-built loggers, which represent a non-negligible part $(16.1 \%)$ of the devices used by research groups. The reliance on home-made biologgers is exacerbated by the fact that biologgers are a small market, rendering commercial biologgers expensive or, another consequence of a reduced demand, produced with limited capacities (e.g. transducers) that do not always meet the specific needs of the researchers.

In summary, only rich countries seem able to afford the luxury of developing and using biologging technology. For other countries, collaborations are the principal means by which they can gain access to biologgers, but this is problematic. Promoting international collaboration between biologging users is, therefore, a necessity for the forthcoming decades. At a grand scale, we hope that funding agencies from rich countries sponsoring international projects better value those projects that propose to develop biologging tools and to share these tools with less fortunate countries. This is especially relevant since endangered species, for which information is sometimes urgently required, are commonly found in those countries that do not possess the financial means to purchase biologgers. 


\section{BIOLOGGING IN THE 'PUBLISH OR PERISH’ WORLD}

Kooyman's (2004) review of the origin and development of biologging noted that the number of biologging studies published in peer-reviewed journals was almost non-existent, apart from a few isolated articles during the 1960s and 1970s, most of these produced by Kooyman or members of his team. The number of biologging studies began to rise from the mid-1980s, increasing drastically until a peak in the year 2000 . This trend is similar to that reported by Shaffer \& Costa (2006), who based their study on a regional database of marine mammal diving studies that stopped in 2000. The decline in the number of publications following 2000 was mirrored by an increase in the impact factors of the journals in which such studies were published (Fig. 4). In Fig. 4, we used the impact factor of each journal from the year of publication of the study. We could not trace impact factors of journals prior to 1991, but the small number of publications before this date would not have yielded representative figures (especially if one considers that the impact factor of 1965 would be determined by only one publication: Kooyman 1966). Nonetheless, it would be unwise to conclude that quality has recently replaced quantity in biologging studies, not least because journal impact factors tend to increase over time (Fig. 4). Moreover, it is plausible that the first biologging studies, although they might have been more descriptive than some later studies, could have been published more easily in high-profile journals, while this has become much more difficult nowadays, especially since an increasing number of journals only accept hypothesis-driven studies for publication.

It is interesting to note that diving studies that use visual observations of diving animals (i.e. non-biologging) have remained relatively constant throughout the years, even though increasing miniaturization of biologgers should allow researchers to target a greater variety of species, even those of increasingly small sizes. This is presumably because observations still play an important part in understanding the diving ecology of animals, they are inexpensive, and are a logistically feasible option for very small species.

More than $60 \%$ of the references compiled in the Penguiness Book were published in only 10 journals (out of a total of 68 journals indexed in the database), with the Canadian Journal of Zoology, a generalist biological journal, comprising $13.5 \%$ of the total (Fig. 5). There was also an interesting dichotomy in the main type of the journals that published biologging works: more than half of the studies were either published in generalist journals (e.g. Journal of Experimental Biology, Journal of Zoology) or in what we defined as taxon-specific journals (e.g. Ibis or Marine Mammal Science). Marine and polar journals were the next most widespread repositories of biologging studies. This was not unexpected, since biologging was initially developed to help understand animals exploiting

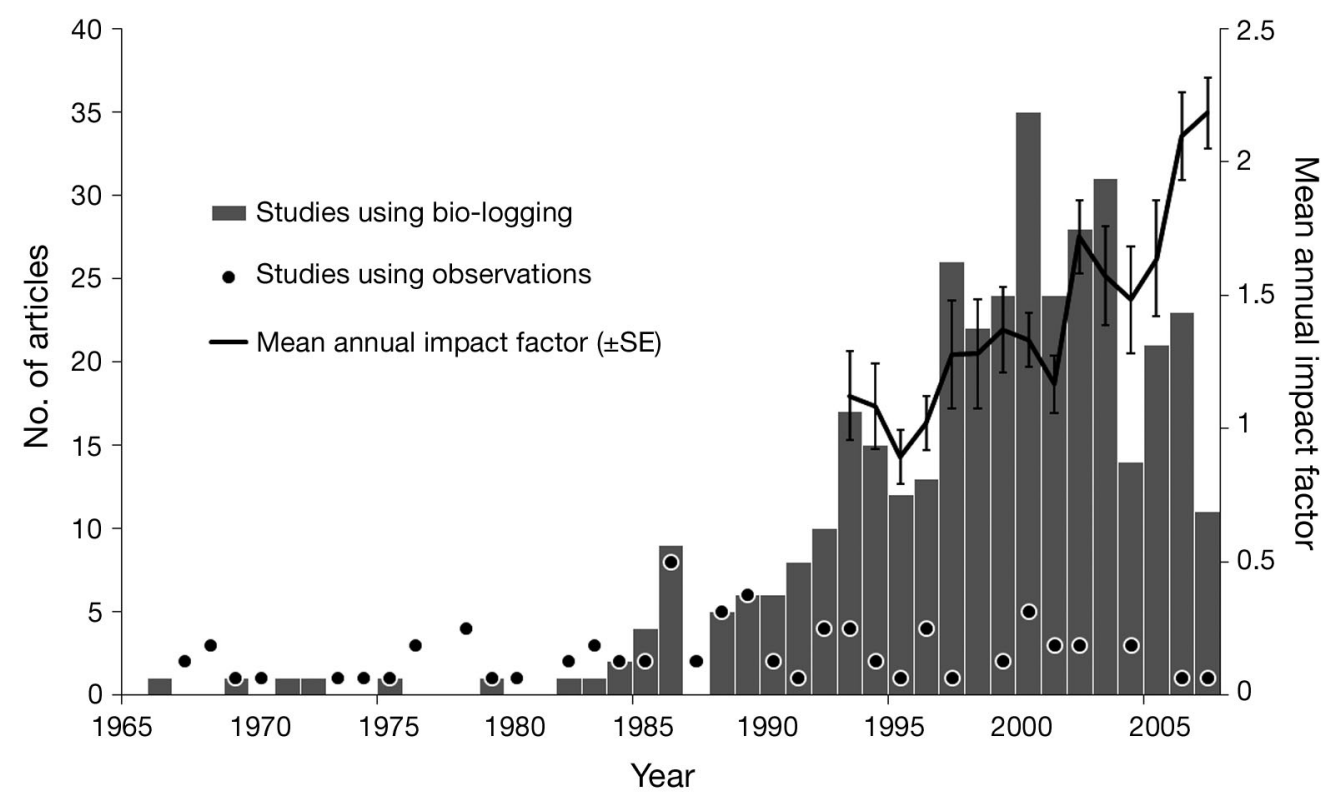

Fig. 4. Annual number of articles using biologging approaches (bars) or simple visual observations (black dots) to investigate diving activity, and mean $( \pm \mathrm{SE})$ weighed annual impact factor of the journals in which biologging studies were published (line). Note that impact factors (IF) of journals (at least those of the 10 most represented journals) increase significantly over time $(x)$ following IF $=0.06 x-116.9\left(\mathrm{R}^{2}=0.96, F_{1,13}=291.7, \mathrm{p}<0.001\right)$ 


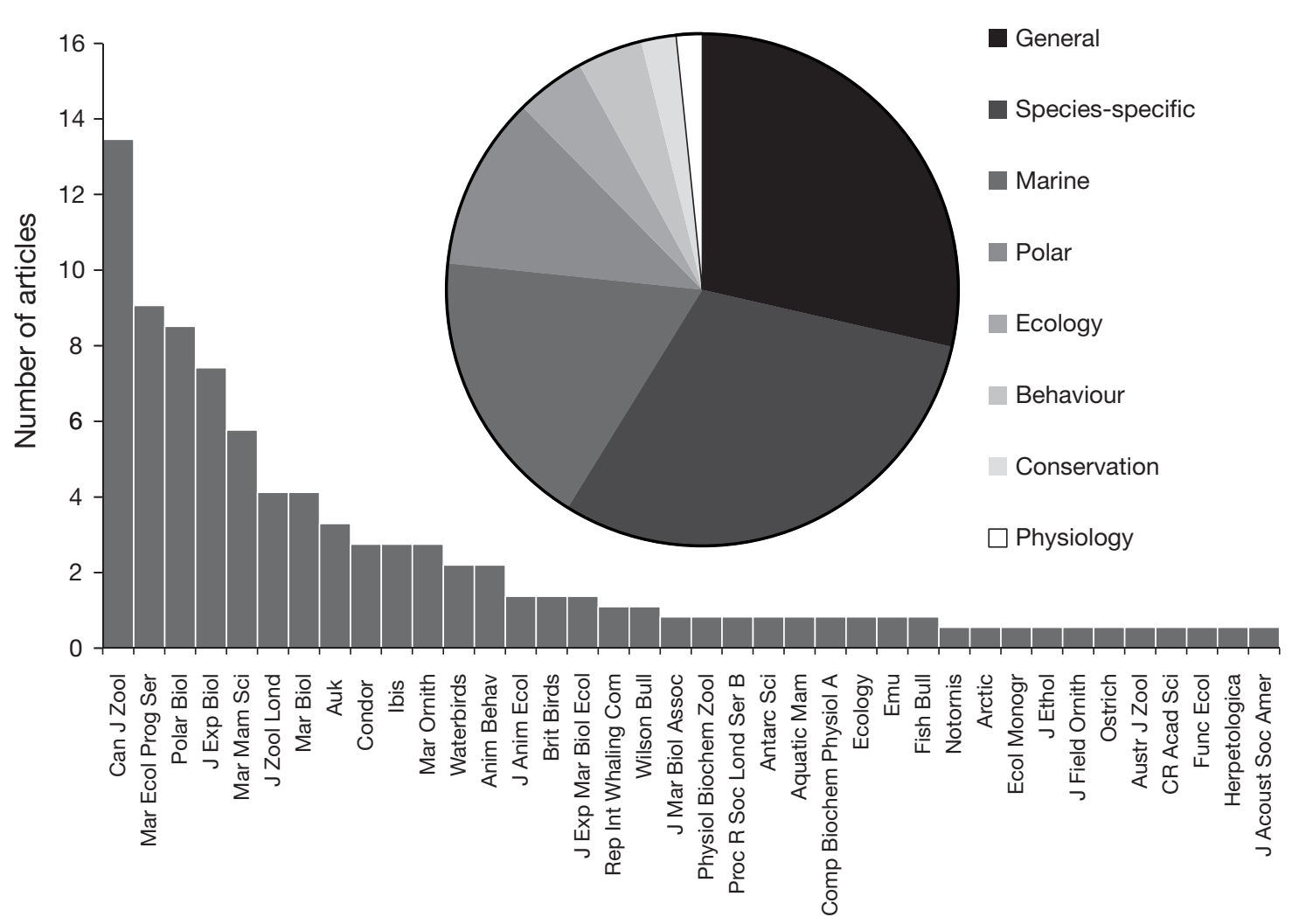

Fig. 5. Distribution of the biologging articles by journals (bars) and by journal category (pie chart). See text for definition of taxon-specific journals

inaccessible milieu like marine and polar environments (one of the very first species to be monitored using biologging was the Weddell seal Leptonychotes weddellii, Kooyman 1966).

In contrast, journals that cover a specific scientific discipline were underrepresented, although there are biases in the way these journals are covered in the Penguiness Book. Hence, the number of biologging studies in physiological journals was artificially underestimated due to the fact that the Penguiness Book only compiles studies that have been conducted in the wild (see 'Introduction'). This process retains only the ecophysiological studies in which diving activity is measured in a natural setting, including those few studies that use semi-captive conditions (like the isolated dive hole in Antarctica, see Ponganis et al. 2003) and eliminates an appreciable number of laboratorybased investigation in which biologging tools other than depth recorders may have played a crucial role. However, this poor representation was surprising in the case of journals with a conservation-oriented aim, since biologging data can provide substantial information that could help understand and better protect vulnerable aquatic or semi-aquatic species (see Cooke 2008 for review). As mentioned in the 'Introduction', the application of biologging to studies of vulnerable species is non-negligible and we could expect a greater representation of this approach in conservation journals. Indeed, data obtained in the wild from biologging approaches are extremely valuable to conservationists as they provide real estimates of the situation in the environment, information that can be compared to the outcomes of theoretical models. Hopefully, such an approach will become more widely used in the forthcoming years.

\section{CONCLUSIONS}

There are a number of limitations to the use of our index to determine the extent of biologging in today's scientific community. For instance, the Penguiness Book does not represent an exhaustive compilation of all diving studies published in peer-reviewed journals, although it does account for a substantial number of them. In addition, approximately $8 \%$ of studies that used biologging for diving studies but did not provide data in a format that could be compiled in the Penguiness Book (e.g. no explicit values of diving depth or duration, or experiments conducted in captivity) were 
not taken into account. However, these studies were generally concerned with various species already covered in other publications used in the present review and were likewise published in journals we have cited. Excluding them would have modified our figures only by a degree. Databases like the Penguiness book or that edited by Shaffer \& Costa (2006), unfortunately would not allow us to examine in further detail the characteristics of the biologging studies they contain. Information such as the resolution of biologgers used or the characteristics of the individuals monitored (sex, age, size) are indeed not always compiled into the database. In this respect, the sharing of raw data by research groups worldwide would certainly enhance our knowledge of species' diving activity and, at the same time, allow us to establish more accurate reports such as the present review.

Finally, although the Third Biologging Science Symposium included only 5 non-diving oral presentations of a total of 90 (http://biologging.wordpress.com/ abstracts/), we expect that increases in the use of a biologging approach in the future will not necessarily be applied to diving species or for the purpose of measuring diving activity per se. While such a diversification will make it increasingly difficult to compile biologging studies, it is a sign that this field is becoming increasingly recognized and used across scientific disciplines.

Acknowledgements. We thank 2 anonymous referees, D. Costa and S. Shaffer for constructive comments on the manuscript and A. Muse for suggesting this review.

\section{LITERATURE CITED}

Ainley DG (1983) Breeding biology of the Adelie penguins. California Press, London

Block BA (2005) Physiological ecology in the 21st century: advancements in biologging science. Integr Comp Biol 45: 305-320

Brischoux F, Bonnet X, Cook TR, Shine R (2007) Snakes at sea: diving performances of free-ranging sea kraits. Proc 11th Annu Meeting on Health, Science \& Technology, Université François Rabelais, Tours, p 5-20

Burger AE, Shaffer SA (2008) Application of tracking and data-logging technology in research and conservation of seabirds. Auk 125:253-264

Editorial responsibility: Rory Wilson,

Swansea, UK
Cooke SJ (2008) Biotelemetry and biologging in endangered species research and animal conservation: relevance to regional, national, and IUCN Red List threat assessments. Endang Species Res 4:165-185

Cooke SJ, Hinch SG, Wikelski M, Andrews RD, Kuchel LJ, Wolcott TG, Butler PJ (2004) Biotelemetry: a mechanistic approach to ecology. Trends Ecol Evol 19:334-343

Griffiths R, Tiwari B (1993) Primers for the differential amplification of the sex determining region $Y$ gene in a range of mammal species. Mol Ecol 2:405-406

- Griffiths R, Double MC, Orr K, Dawson RJ (1998) A DNA test to sex most birds. Mol Ecol 7:1071-1075

Hawkins PJ (2004) Bio-logging and animal welfare: practical refinements. Mem Natl Inst Polar Res 58(Spec Issue): $58-68$

Ineich I (2004) Les serpents marins. Institut Oceanographique, Monaco

> King DA (2004) The scientific impact of nations. Nature 430: 311-316

- Kooyman GL (1966) Maximum diving capacities of the Weddell seal, Leptonychotes weddelli. Science 151:1553-1554

Kooyman GL (2004) Genesis and evolution of bio-logging devices: 1963-2002. Mem Natl Inst Polar Res 58(Spec Issue): $15-22$

McMahon CR, Field IC, Bradshaw CJ, White GC, Hindell MA (2008) Tracking and data-logging devices attached to elephant seals do not affect individual mass gain or survival. J Exp Mar Biol Ecol 360:71-77

Naito Y (2004) Bio-logging science. Mem Natl Inst Polar Res 58(Spec Issue):118-132

Ponganis PJ, Dam RPV, Levenson DH, Knower T, Ponganis K, Marshall G (2003) Regional heterothermy and conservation of core temperature in emperor penguins diving under sea ice. Comp Biochem Physiol A 135:477-487

Ropert-Coudert Y, Wilson RP (2005) Trends and perspectives in animal-attached remote sensing. Front Ecol Environ 3: $437-444$

Ropert-Coudert Y, Kato A, Wilson RP (2006) The Penguiness Book. Available at http://polaris.nipr.ac.jp/ penguin/ penguiness/

Rutz C, Hays GC (2009) New frontiers in biologging science. Biol Lett doi: 10.1098/rsbl.2009.0089

> Shaffer SA, Costa DP (2006) A database for the study of marine mammal behavior: gap analysis, data standardization, and future directions. IEEE J Ocean Eng 31: 82-86

Stearns SC (1992) The evolution of life history. Oxford University Press, New York

Wilson RP, McMahon CR (2006) Measuring devices on wild animals: What constitutes acceptable practice? Front Ecol Environ 4:147-154

Wilson RP, Grémillet D, Syder J, Kierspel MM and others (2002) Remote-sensing systems and seabirds: their use, abuse and potential for measuring marine environmental variables. Mar Ecol Prog Ser 228:241-261

Submitted: December 4, 2008; Accepted: February 16, 2009

Proofs received from author(s): April 17, 2009 